\title{
Cognitive dysfunction in homeless adults: a systematic review
}

\author{
Sean Spence MD MRCPsych Richard Stevens PhD Randolph Parks PhD
}

J R Soc Med 2004;97:375-379

\section{SUMMARY}

Homelessness is associated with multiple adversities that might impact upon brain function. We performed a review of published work to assess evidence of cognitive dysfunction among adults who are homeless. Despite liberal inclusion criteria only seventeen publications were identified, these describing eighteen samples mainly from the USA. Although the total number of individuals studied is small (about 3300) and the samples are heterogeneous, most studies indicate a considerable burden of cognitive dysfunction among homeless people. Such dysfunction might be expected to impact upon their ability to reintegrate into society, thereby undermining policies of inclusiveness. In clinical practice, assessment of homeless adults should include their cognitive state.

\section{INTRODUCTION}

The 1948 Universal Declaration of Human Rights describes access to adequate housing as 'essential'. ${ }^{1}$ Yet, globally, about one billion people are poorly housed, of whom 100 million live on the streets. ${ }^{2}$ According to UNICEF $^{3}$ every night in the USA there are 750000 homeless people; in Canada's largest city, Toronto, emergency shelters for the homeless admitted an average of 6500 people per night in 1997; and in the European Union, before its expansion in 2004, about 3 million people were without a permanent home. In 2001 the number of homeless people in England was reckoned at over $440000 .^{4}$

Those who are homeless and also mentally ill are among the most marginalized members of society. Indeed, one of the stated aims of the UK Government's National Service Framework for Mental Health ${ }^{5}$ and the Social Exclusion Unit ${ }^{6}$ is to reduce such exclusion. The success of such enterprises may, at least partly, depend upon the capacity of affected individuals to recover and reintegrate into their communities. With this in mind, we set out to examine the evidence that cognitive function might be impaired in those who are homeless. Here, 'cognitive function' comprises those neuropsychological processes supporting mental activity-e.g. memory and attention-and so-called 'executive' functions (the planning and control of behaviour). Given the pivotal role of executive functions in the control of voluntary behaviours, ${ }^{7}$ we posited that

Academic Clinical Psychiatry, Division of Genomic Medicine, University of Sheffield, The Longley Centre, Norwood Grange Drive, Sheffield S5 7JT, UK

Correspondence to: Dr Sean Spence

E-mail: s.a.spence@sheffield.ac.uk these might be dysfunctional in those who are unable to find or retain permanent accommodation.

The present study examines evidence for an association between homelessness and cognitive deficit in adults. It should be noted at the outset that no studies have been formally designed to investigate cognitive impairment as a risk factor for becoming homeless (according to our methodology, described below) and little work has been done on the impact of homelessness upon cognition per se (see below). Hence, for the time being the question of causality cannot be resolved.

\section{METHODS}

\section{Searching}

A systematic review of published sources was conducted with guidance from standard texts. ${ }^{8-10}$ The following electronic resources were searched to the earliest date possible in each case: PsycINFO, MEDLINE, EMBASE, Social Science Citation Index, Science Citation Index, CINAHL, Biological Abstracts, ASSIA, INSPEC, HMIC/ DH Data, British Nursing Index, SPORT Discus, AMED, Econlit. Other resources included the Cochrane library, NHS National Research Register, EBM Reviews-ACP, and Journal Club. The following were searched for in the titles, abstracts and any subject heading fields in each database: (homeless* or roofless* or fixed abode* or hostel* or 'bed and breakfast*' or night shelter* or hotel* or housing benefit* or street dwell* or tramp or tramps or vagrant* or vagabond*) AND (cognit* or 'executive function*'). Almost all the records identified were located in PsycINFO, Medline, Citation Indexes, EMBASE and CINAHL. 


\section{Study selection and data synthesis}

On the basis of pilot searches we expected the published work to be scarce, so our inclusion criteria were liberal. All studies published in journals were selected that involved homelessness and cognitive function, irrespective of hypotheses tested. Our central research question required the reporting of cognitive test data; hence, in the final review we included only those studies where cognitive assessments had been performed among a cohort of individuals (at least 3) in the context of homelessness. Since statistical combination of studies should not form a prominent component in the synthesis of observational studies, ${ }^{8}$ no attempt was made at meta-analysis of the data found in the included studies.

\section{RESULTS}

\section{Studies identified}

Initial searches produced a crude total of 488 records (taking no account of duplication). This set contained about 250 different records. From an initial screening of abstracts for basic relevance, 80 records were examined. After the full text of these 80 papers had been screened, 21 were included at the data extraction stage. One of these reported two separate studies, ${ }^{11}$ so these were differentiated, giving a preliminary total of 22 studies. 5 further studies were identified from the reference sections of those already recruited, giving an intermediate total of 27. The papers remaining fell into two broad categoriesthose reporting studies of children $(n=9$, to be reported elsewhere) and those reporting studies of adults $(n=17),{ }^{11-26}$ with one yielding data on both. ${ }^{27,28}$ The setting of the final 18 'adult' studies could be divided between USA $(n=11)^{11-20,27-28}$ and the rest of the world $(n=7) .{ }^{11}, 21-26$ The USA contributed more than $70 \%$ of adults included.

\section{Demographic factors}

Definitions of homelessness varied across studies, incorporating those who were literally 'roofless' 24 and those for whom accommodation was inherently unreliable or temporary (e.g. in the hostels of London). ${ }^{22,23}$ Numerically, most studies concerned hostel residents and the majority of those studied were male $(81 \%$ of adults, where gender is clearly reported). Ethnicity is not always reported, but where it is, mostly in USA and UK studies, there is an over-representation of 'visible' minorities. ${ }^{12,13,16,18-20,22}$

\section{Sample heterogeneity}

In the context of the total number of homeless worldwide, the number of homeless adults studied from a cognitive perspective seems rather small-around 3300 for whom data are fully reported. Also, studies have varied in their orientation towards the mentally ill. While some have attempted to exclude those with psychiatric disorders, ${ }^{17,19}$ others have specifically targeted this group. ${ }^{18}$ Similarly, some workers have attempted to exclude those abusing alcohol or illicit substances ${ }^{17}$ while most have included them. Given the high prevalence of psychiatric disorders, including the addictions, among the homeless, ${ }^{29}$ it is pragmatic to include those so affected, since otherwise the surveyed sample is unlikely to represent real-world circumstances (at least in the urban West). Many studies reviewed have recorded high rates of depression, 11,14,18,20,22-24,27 schizophrenia, ${ }^{11-13,18,21-24}$ alcohol dependence ${ }^{12,14-15,20,23-24}$ and head injury ${ }^{23}$ among the homeless. Hence, there is considerable psychopathology but also heterogeneity among the samples assayed. Few researchers have incorporated control groups or comparison data. These features may be related to the sampling methods applied, which have generally comprised crosssectional surveys of a given facility (e.g. a hostel or clinic), with only a minority of groups attempting an epidemiological approach. ${ }^{11,13,24}$

\section{Global cognitive impairment}

Notwithstanding the caveats noted above, there is the impression of greater comparability across studies in terms of cognitive assessment. Of the 18 studies assayed, 10 (reported in nine papers) have used the same screening tool-the Mini Mental State Examination (MMSE). ${ }^{11-13,20-24,26}$ Although an insensitive indicator of cognitive impairment, this provides a brief easy-toadminister test battery that can be incorporated into a clinical assessment and possesses high inter-rater reliability. It is not so useful for the detection of focal cognitive deficits (e.g. aphasia) and is insensitive to frontal lobe disorders. ${ }^{30}$ Among adults living in the community, the proportion expected to exhibit deficits on the MMSE is about $2-3 \%$, whereas most studies of the homeless have shown much higher rates, ${ }^{11,13,20,21,23,24,26}$ reaching $30-40 \% .^{20,21}$ Only 2 of these 10 studies incorporate comparative data. ${ }^{12,13}$ Both are American and utilize data from the Epidemiological Catchment Area Survey; both report increased rates of cognitive impairment among the homeless. In the Koegel study, ${ }^{13}$ the comparison data relate to domiciled 'alcoholics', the latter exhibiting less cognitive impairment than an index group of homeless 'alcoholics'. This is the most informative controlled study available.

To summarize the MMSE data, in most studies of homeless adults those sampled exhibit high rates of generalized cognitive impairment. 


\section{Focal cognitive impairment}

On the question of focal cognitive impairment, notably few studies have employed neuropsychological tests that might be expected to detect frontal lobe (executive) impairment. The latter would include the Wisconsin Card Sort Test, ${ }^{18}$ the Trails $\mathrm{B}^{20}$ and the Stroop. ${ }^{15}$ Such tasks require the subject to apply new strategies in adapting to test conditions, ${ }^{18}$ and to inhibit inappropriate responses to test stimuli. ${ }^{15,18,20}$ They are quintessentially tests of 'higher' brain function. ${ }^{30}$ Of the three studies incorporating these instruments, two have pointed to substantial deficits among the homeless, ${ }^{18,20}$ although neither included controls. The third study, though detecting a decrement in performance, found a similar level of impairment among domiciled (mentally ill) controls. ${ }^{15}$ Indeed, the authors even suggested that their homeless (mentally ill) sample might be superior to the domiciled in certain cognitive domains-hence their ability to survive in a hostile environment. It may be relevant that this paper reports a study of 'veterans', ${ }^{15}$ who at one time would have been pronounced fit for armed service; presumably, therefore, their cognitive function had been good before they became homeless.

\section{Studies of IQ}

Studies reporting actual or estimated numerical values for adult intelligence ${ }^{14,15,17,18,31}$ found IQ in the homeless to be in the low average to average range.

Two studies ${ }^{16,22}$ specifically compared measures of premorbid intelligence and current intelligence. Both showed a significant decline in intelligence in those individuals with mental illness (Adams et al. ${ }^{22}$ from average to borderline; Bremner et al. ${ }^{16}$ from average to low average). Bremner and colleagues ${ }^{16}$ showed a drop in those without a diagnosis, in those with alcohol dependence and concurrent drinking, and in those with 'other diagnoses' (e.g. depression, anxiety). In the same study, IQ drop, but not current IQ, correlated with duration of rooflessness. In the Adams study, ${ }^{22}$ individuals with psychosis had suffered a greater intellectual decline from their premorbid levels of function than those without psychosis. No decline was evident in the latter group. ${ }^{22}$

\section{DISCUSSION}

Is there an association between cognitive dysfunction and homelessness? In attempting to answer this question we must first acknowledge the limitations of the current review. Most studies identified by us have tended to utilize cross-sectional designs to sample subjects in specific settings (e.g. hostels or clinics) and most reflect conditions in the USA. Also, our searches were conducted in Englishlanguage databases only and, consequently, there is a bias towards research published in English in general, and to those foreign-language articles that have been indexed electronically. Thus, any answer to the above question is conditional and not necessarily applicable to non-'Western' settings. However, with respect to adults, it does seem likely that there is an association between homelessness and global cognitive impairment. Most studies support such a conclusion.

There is, of course, a question as to whether such cognitive impairment is in any way specific to the homeless or whether it is similarly prevalent among other at-risk groups (e.g. people living in poverty). With the small number of studies available for review, it would be premature to draw any firm conclusions. Indeed, while homeless people are likely to experience adverse circumstances, there is not necessarily any a priori reason why they should exhibit a pattern of cognitive deficit distinct from the poor or otherwise disadvantaged, and perhaps this does not matter anyway. The medical questions pertinent to the homeless are: to what extent is cognitive/brain impairment present; what can be done to reverse/ameliorate it; and how will persistent deficits impact upon social function/ reintegration? These would seem fitting questions also for medical research, yet they seem to have attracted little attention. To put things in perspective: schizophrenia is a severe mental disorder affecting approximately 1 in 100 adults worldwide, ${ }^{32}$ yet studies of cognitive dysfunction in this disorder have reported on more than 7000 patients (according to very strict defining criteria). ${ }^{33}$ The homeless may comprise as many of the world's population, ${ }^{2}$ yet their cognitive function has been reported in a little over 3000 adults (and these ascertained by use of widely variable inclusion criteria). Given the number of homeless adults living in the world, it is surprising that so few studies have examined their cognition.

In the clinic or casualty department, the presence of global cognitive impairment might be expected to impact upon the retention of new information. Hence, it may make little sense to discharge a homeless man with alcohol problems from the casualty department, expecting him to attend an alcohol service the next morning, without providing at least some written information or ensuring some means of outreach follow-up. Similarly, to discharge the homeless person with schizophrenia from hospital, in the hope that she will find and attend the housing department of the local authority, may be overoptimistic. In our own clinical practice with the roofless we have encountered people with schizophrenia who have been left untreated for a decade, ${ }^{34}$ often because they do not adhere to the outpatient model of psychiatric services.

The extent of executive (global) cognitive impairment in homeless adults requires further elucidation. There are only three studies pertaining to this important question. ${ }^{15,18,20}$ If people are to change their circumstances, to learn new skills 
and to break destructive patterns of behaviour then it is the executive system which is particularly implicated in such cognitive flexibility. 7,35 The MMSE is not the best way to assess executive function and may accrue type II errors (false negatives). ${ }^{20}$ There is a need for studies that utilize specific probes of executive function - e.g. the Trails B, Stroop and Wisconsin Card Sort Test. When such tests are applied, then the evidence suggests that many homeless adults are executively impaired $(80 \%$ in the Gonzalez study ${ }^{20}$ ).

We cannot comment on whether cognitive dysfunction predisposes people to homelessness, for no prospective studies have addressed this question. Similarly, evidence of a direct impact of homelessness upon cognition is very limited. The studies that we have identified among the homeless mentally ill do, however, suggest that extent of cognitive decline is related to indices of homelessness. ${ }^{22,23}$ Similarly, and despite its considerable face validity, whether or not cognition impacts upon the ability to resettle can only be inferred indirectly from cross-sectional data. ${ }^{21}$

What is to be done? Our findings suggest that it may be prudent to assess cognition when encountering patients who are homeless, especially if they are also mentally ill. While the busy clinical setting may constrain the extent of cognitive assessment, the MMSE and a test of verbal fluency might be performed within 5 minutes and reveal signs of dysfunction. ${ }^{30}$ In psychiatric services that assess homeless people, access to neuropsychological assessment seems essential. More than the symptoms of psychosis, it is the extent of cognitive dysfunction that predicts social outcome among those with schizophrenia ${ }^{36}$ and there is no reason to assume that this is any less true for patients who are homeless.

Acknowledgment Sheffield Care Trust funded this study.

\section{REFERENCES}

1 United Nations. Universal Declaration of Human Rights. Article 25 [http:// www.un.org/Overview/rights.html]

2 Begin P, Casavant L, Chenier NM, Dupuis J. Homelessness. Library of Parliament (Canada). Parliamentary Research Branch, 1999 [http:// www.parl.gc.ca/information/library/BRBpubs/prb991-e.htm]

3 Alston P. Progress of Nations 1998. Industrialized Countries. UNICEF [http://www.unicef.org/pon98/indust1.htm]

4 Shelter. Housing and Homelessness in England: the Facts. July 2002 [http:// www.shelter.org.uk/images/pdfs/factsheets/ Homeless_in_England_july_02.pdf]

5 Department of Health. National Service Framework for Mental Health [http://www.doh.gov.uk/nsf/mentalhealth.htm]

6 Social Exclusion Unit [http://www.socialexclusionunit.gov.uk]

7 Spence SA, Hunter MD, Harpin G. Neuroscience and the will. Curr Opin Psychiatry 2002;15:519-26

8 Egger M, Smith GD, Altman DG, eds. Systematic Reviews in Health Care: Meta-analysis in Context, 2nd edn. London: BMJ Publishing, 2001
9 Glasziou P, Irwig L, Bain C, Colditz G. Systematic Reviews in Health Care: a Practical Guide. Cambridge: Cambridge University Press, 2001

10 NHS Centre for Reviews and Dissemination. Undertaking Systematic Reviews of Research on Effectiveness: Guidance for those Carrying out or Commissioning Systematic Reviews. Report No. 4, 2001

11 Muñoz M, Vazquez C, Koegel P, Sanz J, Burnam MA. Differential patterns of mental disorders among the homeless in Madrid (Spain) and Los Angeles (USA). Soc Psychiatry Psychiatr Epidemiol 1998;33: 514-20

12 Fischer PJ, Shapiro S, Breakey WR, Anthony JC, Kramer M. Mental health and social characteristics of the homeless: a survey of mission users. Am J Pub Health 1986;76:519-24

13 Koegel P, Burnam A, Farr RK. The prevalence of specific psychiatric disorders among homeless individuals in the inner city of Los Angeles. Arch Gen Psychiatry 1988;45:1085-92

14 Louks JL, Smith R. Homeless: Axis I disorders. Hosp Commun Psychiatry 1988;39:670-71

15 Foulks EF, McCown WG, Duckworth M, Sutker PB. Neuropsychological testing of homeless mentally ill veterans. Hosp Commun Psychiatry 1990;41:672-5

16 Boccellari AA, Dilley JW. Management and residential placement problems of patients with HIV-related cognitive impairment. Hosp Commun Psychiatry 1992;43:32-7

17 Cotman A, Sandman C. Cognitive deficits and their remediation in the homeless. J Cogn Rehab 1997; 15:16-24

18 Seidman LJ, Caplan BB, Tolomiczenko GS, et al. Neuropsychological function in homeless mentally ill individuals. J Nerv Ment Dis 1997; 185:3-12

19 Douyon R, Guzman P, Romain G, et al. Subtle neurological deficits and psychopathological findings in substance abusing homeless and non-homeless veterans. J Neuropsychiatry Clin Neurosci 1998;10:210-15

20 Gonzalez EA, Dieter JNI, Natale RA, Tanner SL. Neuropsychological evaluation of higher functioning homeless persons: a comparison of an abbreviated test battery to the Mini Mental State Exam. J Nerv Ment Dis 2001; 189:176-81

21 Teesson M, Buhrich N. Prevalence of cognitive impairment among homeless men in a shelter in Australia. Hosp Commun Psychiatry 1993;44:1187-9

22 Adams CE, Pantelis C, Duke PJ, Barnes TRE. Psychopathology, social and cognitive functioning in a hostel for women. Br $J$ Psychiatry 1996;168:82-6

23 Bremner AJ, Duke PJ, Nelson HE, Pantelis C, Barnes TRE. Cognitive function and duration of rooflessness in entrants to a hostel for homeless men. BrJ Psychiatry 1996;169:434-9

24 Fichter MM, Koniarczyk, Greifenhagen A, et al. Mental illness in a representative sample of homeless men in Munich, Germany. Eur Arch Psychiatry Clin Neurosci 1996;246:185-96

25 Geddes JR, Newton JR, Bailey S, Freeman C, Young G. The chief scientist reports. . . Prevalence of psychiatric disorder, cognitive impairment and functional disability among homeless people resident in hostels. Health Bull (Edinb) 1996;54:276-9

26 Buhrich N, Hodder T, Teesson M. Prevalence of cognitive impairment among homeless people in inner Sydney. Psychiatr Serv 2000;51:520-1

27 San Agustin M, Cohen P, Rubin D, Cleary SD, Erickson CJ, Allen JK. The Montefiore community children's project: a controlled study of cognitive and emotional problems of homeless mothers and children. J Urban Health 1999;76:39-50

28 Rubin DH, Candace J, San Agustin M, Cleary SD, Allen JK, Cohen P. Cognitive and academic functioning of homeless children compared with housed children. Pediatrics 1996;97:289-94

29 Kass F, Silver JM. Neuropsychiatry and the homeless. J Neuropsychiatry Clin Neurosci 1990;20:15-19 
30 Hodges JR. Cognitive Assessment for Clinicians. Oxford: Oxford University Press, 1994

31 Danseco ER, Holden EW. Are there different types of homeless families? A typology of homeless families based on cluster analysis. Fam Relat 1996;47:159-65

32 Jablensky A, Sartorius N, Ernberg G, et al. Schizophrenia: manifestations, incidence and course in different countries. A World Health Organization ten-country study. Psychol Med Monogr Suppl 1992;20:1-97
33 Heinrichs RW, Zakzanis KK. Neurocognitive deficit in schizophrenia. A quantitative review of the evidence. Neuropsychology 1998;12:426-45

34 Girgis S, Spence S. Is it worth treating mentally ill roofless people? Schizophrenia Res 2003;60(suppl):284-5

35 Ainslie G. Breakdown of Will. Cambridge: Cambridge University Press, 2001

36 Green MF. What are the functional consequences of neurocognitive deficits in schizophrenia? Am J Psychiatry 1996;153:321-30 